\title{
Dalbergia ecastaphyllum (L.) Taub. and Symphonia globulifera L.f.: The Botanical Sources of Isoflavonoids and Benzophenones in Brazilian Red Propolis
}

\author{
Gari Vidal Ccana-Ccapatinta ${ }^{1}{ }^{1}$, Jennyfer Andrea Aldana Mejía ${ }^{1}$, Matheus Hikaru Tanimoto ${ }^{1}$, \\ Milton Groppo ${ }^{2}$, Jean Carlos Andrade Sarmento de Carvalho ${ }^{3}$ and Jairo Kenupp Bastos ${ }^{1, *}$ \\ 1 Laboratory of Pharmacognosy, School of Pharmaceutical Sciences of Ribeirão Preto, University of São \\ Paulo (USP), Av. do Café s/n, Ribeirão Preto 14040-903, SP, Brazil; ccana.ccapatinta@usp.br (G.V.C.-C.); \\ j.aldana@usp.br (J.A.A.M.); tanimoto@usp.br (M.H.T.) \\ 2 Laboratory of Plant Systematics, Department of Biology, Faculty of Philosophy, Sciences and Letters at \\ Ribeirão Preto, USP, Av. dos Bandeirantes 3900, Ribeirão Preto 14040-901, SP, Brazil; groppo@ffclrp.usp.br \\ 3 Cooperativa de Apicultores de Canavieiras (COAPER), Av. Burundanga 1900, \\ Canavieiras 45860-000, BA, Brazil; polemj@hotmail.com \\ * Correspondence: jkbastos@fcfrp.usp.br; Tel.: +55-16-3315-4230
}

Received: 27 March 2020; Accepted: 25 April 2020; Published: 28 April 2020

\begin{abstract}
The Brazilian red propolis (BRP) constitutes an important commercial asset for northeast Brazilian beekeepers. The role of Dalbergia ecastaphyllum (L.) Taub. (Fabaceae) as the main botanical source of this propolis has been previously confirmed. However, in addition to isoflavonoids and other phenolics, which are present in the resin of D. ecastaphyllum, samples of BRP are reported to contain substantial amounts of polyprenylated benzophenones, whose botanical source was unknown. Therefore, field surveys, phytochemical and chromatographic analyses were undertaken to confirm the botanical sources of the red propolis produced in apiaries located in Canavieiras, Bahia, Brazil. The results confirmed D. ecastaphyllum as the botanical source of liquiritigenin (1), isoliquiritigenin (2), formononetin (3), vestitol (4), neovestitol (5), medicarpin (6), and 7-O-neovestitol (7), while Symphonia globulifera L.f. (Clusiaceae) is herein reported for the first time as the botanical source of polyprenylated benzophenones, mainly guttiferone E (8) and oblongifolin B (9), as well as the triterpenoids $\beta$-amyrin (10) and glutinol (11). The chemotaxonomic and economic significance of the occurrence of polyprenylated benzophenones in red propolis is discussed.
\end{abstract}

Keywords: isoflavonoids; polyisoprenylated benzophenones; propolis; botanical sources

\section{Introduction}

The red propolis is the second most produced and traded type of propolis in Brazil and constitutes an important commercial asset for northeast Brazilian beekeepers. Apiaries devoted to Brazilian red propolis (BRP) production are frequently located around native populations of the fabaceous species Dalbergia ecastaphyllum (L.) Taub., which produces a red resin that is collected by bees to produce propolis in the beehive [1]. The studies by Daugsch et al. (2008) and Silva et al. (2008) were the first ones to describe, simultaneously in 2008, D. ecastaphyllum as the main botanical source of the BRP [2,3]. These initial studies together with the report of Piccinelli et al. (2011) confirmed the presence of a rich variety of phenolic compounds, in both the propolis and the plant resin, such as chalcones (e.g., isoliquiritigenin), flavonoids (e.g., luteolin, liquiritigenin), isoflavones (e.g., formononetin, biochanin A), isoflavans (e.g., vestitol, neovestitol, 7-O-methylvestitol), pterocarpanes (e.g., medicarpin, homopterocarpin, vesticarpan), and C30 isoflavans (retusapurpurins A and B) [4]. 
Subsequent studies have shown the great qualitative and quantitative variability of the constituents present in red propolis, which are influenced by regional and seasonal factors [5]. Nevertheless, reports on the presence of substantial amounts of polyprenylated benzophenones, such as gutifferone $E$ and oblongifolin A in BRP, have appeared in the literature more frequently [6,7]. Even though the botanical source of these latter constituents was unknown, Piccinelli et al. (2011) inferred from a chemotaxonomic point of view that these compounds must derive from a member of the Clusiaceae family [4]. Important biological activities of BRP extracts, such as antimicrobial, fungicidal, and cytotoxic properties, have been correlated with the occurrence of polyprenylated benzophenones $[6,8,9]$. Thus, establishing its botanical source may help to increase red propolis production and to attain a higher degree of chemical standardization. Therefore, field surveys, phytochemical and chromatographic analyses were undertaken in order to identify the botanical source of polyprenylated benzophenones present in the red propolis produced by apiaries of the Beekeepers Association of Canavieiras (Cooperativa de Apicultores de Canavieiras-COAPER), Bahia, Brazil.

\section{Results}

A filed survey was carried out in March 2019 in order to collect local red propolis samples, the reddish resin of D. ecastaphyllum, and to identify other resin-producing plant species, especially of the Clusiaceae family, located in the surrounding flora of apiaries from the COAPER beekeepers association. The presence of individuals of Symphonia globulifera L.f. was evidenced and its resin was collected, transported to the laboratory, lyophilized, and kept under refrigeration.

\subsection{Isolation of Polyprenylated Benzophenones from Symphonia globulifera and BRP}

Samples of both BRP and S. globulifera resin were extracted with aqueous ethanol $70 \%$ and submitted to partition with solvents of increasing polarities. The hexane fractions were separately submitted to chromatographic procedures that resulted in the isolation of two polyprenylated benzophenones (8 and 9) and two pentacyclic triterpenoids (10 and 11) from both fractions. The structures of the isolated compounds were established based on 1D and 2D-NMR spectroscopy, high-resolution MS, and comparison with the literature data for the polyprenylated benzophenones guttiferone $E$ (8) [10], in a mixture with its double bond position isomer xanthochymol [11], oblongifolin B (9) [12], and the triterpenoids $\beta$-amyrin (10) [13] and glutinol (11) [14]. The NMR spectra of 8 and 9 in $\mathrm{CDCl}_{3}$ displayed abnormalities that disappeared when spectra were recorded in $\mathrm{CD}_{3} \mathrm{OD}+0.1 \%$ trifluoroacetic acid (TFA). The chemical structure of those isolated constituents (8-11), as well as other phenolic compounds (1-7) identified in BRP are displayed in Figure 1.<smiles>O=C1CC(c2ccc(O)cc2)Oc2cc(O)ccc21</smiles>

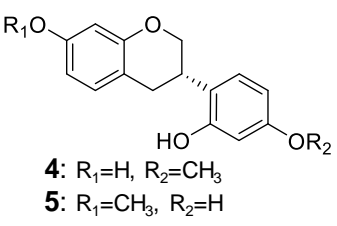<smiles>O=C(/C=C/c1ccc(O)cc1)c1ccc(O)cc1</smiles>
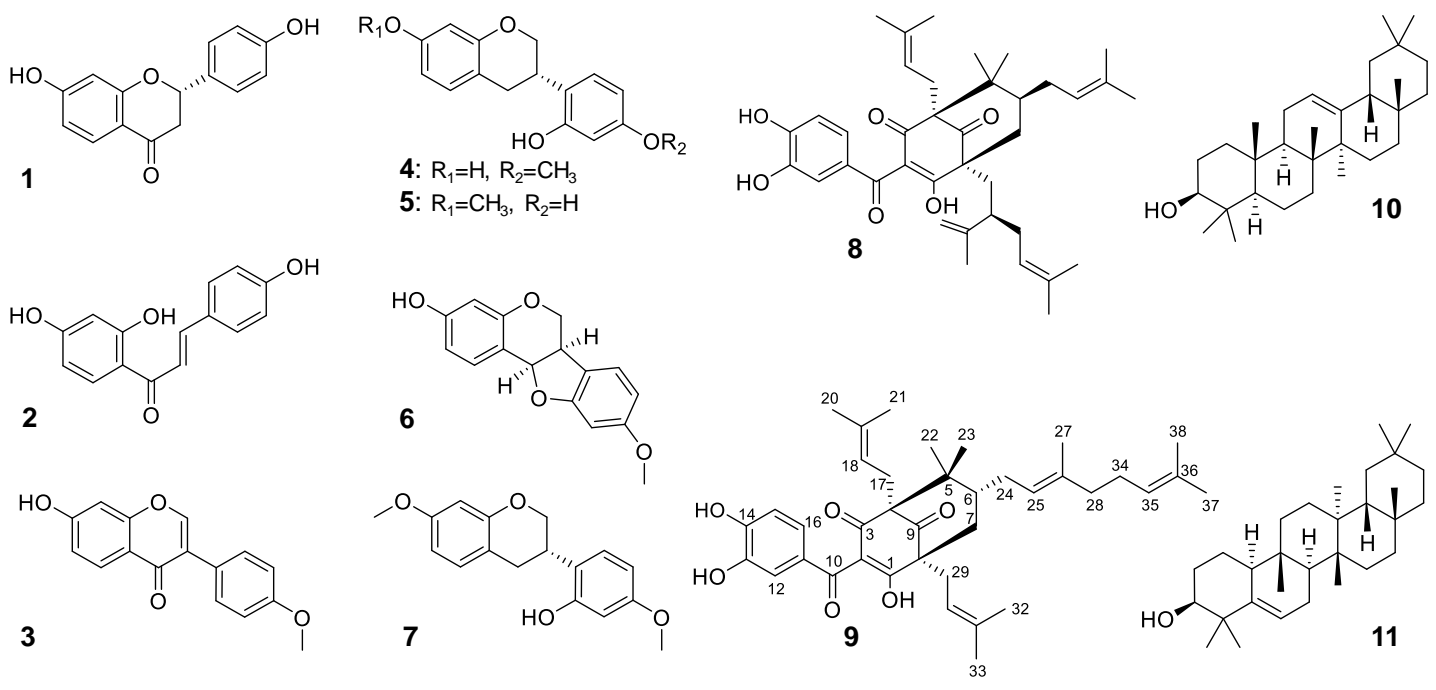

Figure 1. Chemical constituents of Brazilian red propolis. 
The oblongifolins were first isolated from Garcinia oblongifolia by Hamed et al. (2006) [12]. The occurrence of oblongifolin A in samples of BRP was initially reported by Piccinelli et al. (2011), while further publications replicated this finding by LC-MS analyses. However, mass spectrometry of oblongifolins is not enough to identify them, since they bear the same molecular weight, while none of those previous reports have provided NMR data to confirm the occurrence of oblongifolin A in BRP $[4,6-8]$. Therefore, the NMR spectroscopic data of the isolated compound 9 in comparison with published data of oblongifolins A and B is presented in Table S1 (Supplementary Material). The ${ }^{1} \mathrm{H}$ and ${ }^{13} \mathrm{C}$ NMR chemical shifts of these two stereoisomers are almost identical. Nonetheless, significant differences are found in the ${ }^{13} \mathrm{C}$ NMR spectra of these two oblongifolins at $\delta_{\mathrm{C}-6}(47.8$ for $\mathrm{A}$ and 44.2 for B), $\delta_{\mathrm{C}-7}\left(40.8\right.$ for $\mathrm{A}$ and 43.3 for B), and $\delta_{\mathrm{C}-8}$ ( 61.8 for A and 64.3 for B). Similarly, the ${ }^{1} \mathrm{H}$ NMR spectra of oblongifolin B displays a characteristic axial coupling constant for H-7 of $13.0 \mathrm{~Hz}$. Therefore, the isolated compound 9 corresponds to oblongifolin B and its isolation from BRP is here reported for the first time.

\subsection{The Botanical Sources of Brazilian Red Propolis}

The chromatographic profiles of a typical red propolis sample and the resins of D. ecastophyllum and S. globulifera were recorded by a HPLC analysis method (Figure 2); the chromatographic parameters are described in the material and methods section.
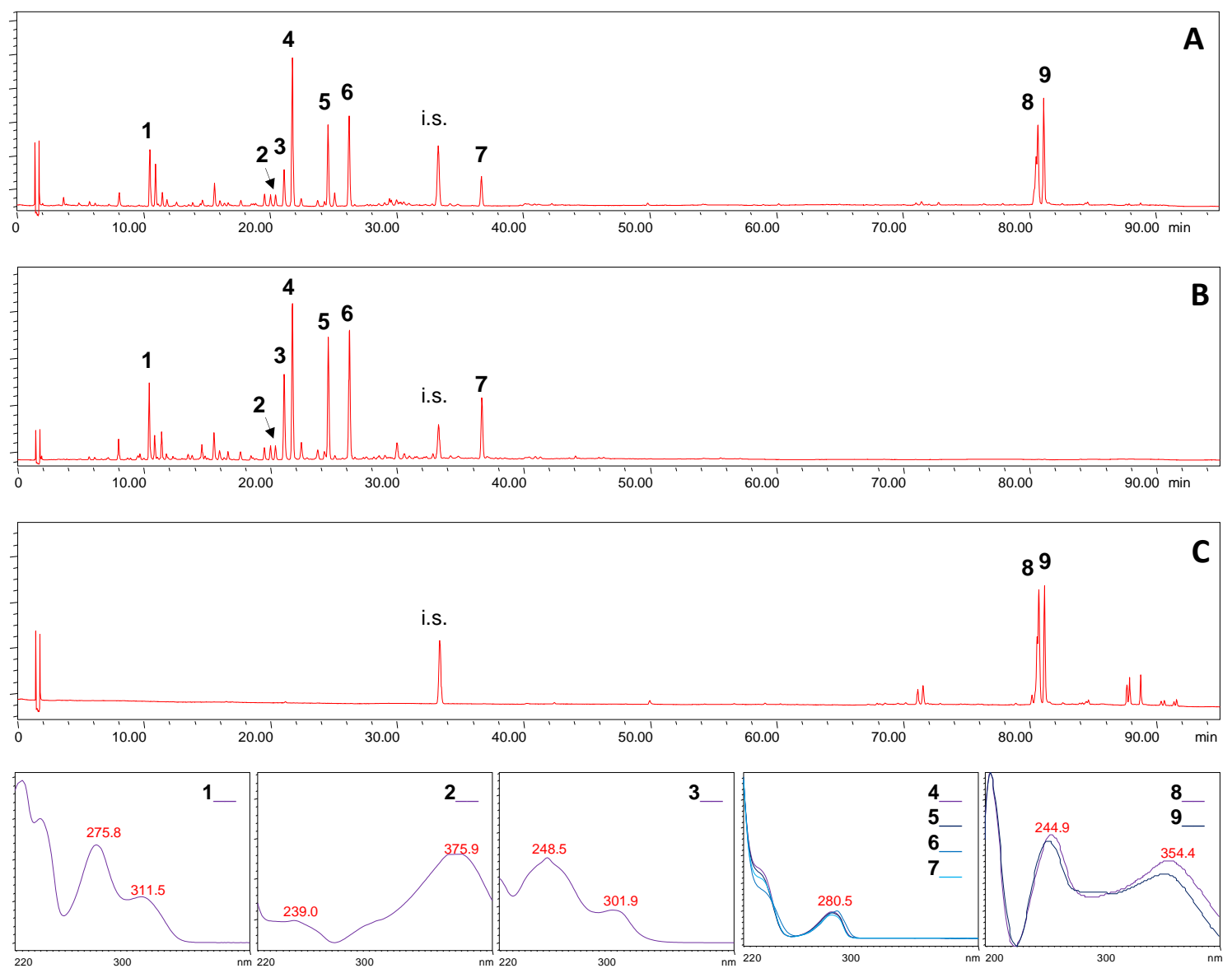

Figure 2. HPLC chromatographic profiles $(275 \mathrm{~nm})$ of Brazilian red propolis $(\mathbf{A})$ in comparison with the resins of Dalbergia ecastaphyllum (B) and Symphonia globulifera (C). Numbers correspond to liquiritigenin (1), isoliquiritigenin (2), formononetin (3), vestitol (4), neovestitol (5), medicarpin (6), 7-O-neovestitol (7), guttiferone E (8), and oblongifolin B (9). UV spectra of compounds 1-9 are displayed at the bottom of the figure. 
Comparison of both the HPLC chromatographic retention times and its corresponding UV spectra with the ones of the standard compounds 1-9 were used for assigning the identity of peaks in the chromatographic profiles of the analyzed samples. The chromatographic prolife of a typical sample of BRP (Figure 2A) displayed at least nine main chromatographic peaks corresponding to phenolic compounds ( 1 and 2$)$, isoflavonoids $(3-5,7)$, a pterocarpane (6) and benzophenones (8-9). The resin of D. ecastaphyllum (Figure 2B) displayed the presence of chromatographic peaks mainly in the region of the HPLC chromatogram from 10 to $40 \mathrm{~min}$, confirming D. ecastaphyllum as the botanical source of liquiritigenin (1), isoliquiritigenin (2), formononetin (3), vestitol (4), neovestitol (5), medicarpin (6), and 7-O-neovestitol (7). In the lipophilic region of the chromatogram (Figure 2C), the resin of S. globulifera displayed two main chromatographic peaks, which were assigned to guttiferone $\mathrm{E}(\mathbf{8})$ and oblongifolin B (9), confirming $S$. globulifera as the botanical source of polyprenylated benzophenones.

\section{Discussion}

The occurrence of the flavonoid liquiritigenin (1); the chalcone isoliquiritigenin (2); the isoflavone formononetin (3); the isoflavans vestitol (4), neovestitol (5), and 7-O-methylvestitol (7); as well as the pterocarpane medicarpin (6) have been previously reported both in BRP and in the resin of its botanical source, D. ecastaphyllum [4]. From a chemotaxonomic point of view, these constituents, especially the isoflavonoids, are characteristic chemotaxonomic markers for Papilionoideae (Fabaceae) subfamily members, to which the Dalbergia genus belongs [15]. The results reported here confirm that the main botanical source of the red propolis produced in the COPAER beekeepers association of Canavieiras is D. ecastaphyllum. This species, which occurs in coastal sand dune and mangrove ecosystems, is present in large populations in the surrounding areas of the apiaries not only in Bahia state but also in the northeast Brazilian localities where red propolis is produced.

On the other hand, the presence of the prenylated benzophenones guttiferone $\mathrm{E}(8)$ and oblongifolin A in commercial samples of BRP was previously reported [6-8] and proposed as a characteristic that could differentiate Brazilian samples from other red propolis, e.g., Cuban propolis [4]. However, the botanical source of polyprenylated benzophenones present in BRP samples was unknown, but it was inferred from a chemotaxonomic point of view that these compounds would be collected by bees from a resin-producing plant belonging to the Clusiaceae family [4]. The isolation of the polyprenylated benzophenones guttiferone E (8) and oblongifolin B (9) reported here from samples of BRP and the resin of $S$. globulifera confirms that the botanical source of these compounds is a member of the Clusiaceae family, in agreement with the chemotaxonomical inference of Piccinelli et al. (2011). The occurrence of compounds 8 and $\mathbf{9}$ in both BRP and S. globulifera was also confirmed here by HPLC analysis. Therefore, the present report identifies, for the first time, S. globulifera as the botanical source of polyprenylated benzophenones of BRP produced in the locality of Canavieiras, Bahia. Unlike the data previously reported, describing the occurrence of oblongifolin A in BRP, we identified, instead, its stereoisomer oblongifolin B (9), the occurrence of which in BRP and S. globulifera is here reported for the first time. Although S. globulifera is a well-known source of polyprenylated benzophenones, this is the first report on the occurrence of guttiferone E (8) in this species. Additionally, this report demonstrates the value of chemotaxonomy for establishing the botanical sources of propolis.

The knowledge of propolis plant sources can help to increase propolis production and to attain a higher degree of chemical standardization [16]. Unlike the Brazilian green propolis, the most produced propolis in Brazil, the market value of red propolis raw material is double the price of green propolis. Therefore, commercial and academic interest has been awakened to extend the area of bee pasture to increase the production of red propolis. The findings reported here demonstrate that BRP does not have only a single botanical source but at least two, D. ecastaphyllum and S. globulifera, which contribute different chemical constituents, principally isoflavonoids and polyprenylated benzophenones, which should be taken into account when installing new beehives for red propolis production in the northeast of Brazil. 


\section{Material and Methods}

\subsection{Field Survey}

A field survey was carried out from 24 March to 5 April 2019 aiming to collect local red propolis samples, the resin of D. ecastaphyllum, and to identify other resin-producing species, especially of the Clusiaceae family, located in the surrounding flora of apiaries from the beekeepers association of Canavieiras (Cooperativa de Apicultores de Canavieiras-COAPER), Bahia, Brazil. The presence of individuals of Symphonia globulifera was evidenced, and their resins were collected, transported to the laboratory, lyophilized, and kept under refrigeration. The plant vouchers were identified and deposited as Symphonia globulifera L.f., SPFR 17770; Dalbergia ecastaphyllum (L.) Taub., SPFR 17,771 at the Herbarium SPFR of the Department of Biology, Faculty of Philosophy, Sciences and Letters at Ribeirão Preto, FFCLRP, University of São Paulo, USP.

\subsection{Extraction and Isolation of Triterpenoids and Polyprenylated Benzophenones}

Two hundred grams of BRP were extracted with aqueous ethanol 70\% (Vetec Química, Rio de Janeiro, Brazil) for three times, 1:10 sample/solvent ratio, and g/mL furnishing $140 \mathrm{~g}$ of crude extract. The extract was then mixed with $200 \mathrm{~g}$ of microcrystalline cellulose (Sigma Aldrich, St. Louis, MO, USA) and submitted to solid-liquid partition with hexanes (Vetec Química, Rio de Janeiro, Brazil), three times of $500 \mathrm{~mL}$, furnishing $23.8 \mathrm{~g}$ of hexane crude fraction. The hexane fraction was then submitted to vacuum liquid chromatography (VLC) by using $150 \mathrm{~g}$ of silica gel (Sigma Aldrich, St. Louis, MO, USA), 40-63 $\mu \mathrm{m}$ particle size, as the stationary phase and mixtures of increasing polarity of hexanes:ethyl acetate $(100: 0 \rightarrow 30: 70)$ as the mobile phase. The eluted fractions were monitored by thin layer chromatography (TLC) and pooled by similarity, generating four fractions: F1 (6 g), F2 (9.26 g), F3 (2.27), and F4 (1.1 g). TLC was carried out on precoated glass TLC silica gel 60F 254 plates (Merck, Darmstadt, Germany), with detection accomplished by visualization with a UV lamp at 254 and $360 \mathrm{~nm}$, followed by spraying with a 1\% solution of 2-aminoethyl diphenylborinate in methanol $(\mathrm{w} / \mathrm{v})$. A portion of fraction F2 (500 mg) was submitted to centrifugal thin-layer chromatography on a Chromatotron device (Harrison Research, USA) by using a 1-mm disk of silica gel (10-40 $\mu$ m particle size) as the stationary phase, and mixtures of increasing polarity of hexanes:ethyl acetate $(100: 0 \rightarrow 30: 70)$ as the mobile phase, affording compounds 8 (70 mg) and 9 (30 mg). A portion of fraction F1 (500 mg) was submitted to flash chromatography on an Isolera One equipment (Biotage, Sweden) by using a 10-g cartridge of silica gel (40 $\mu \mathrm{m}$ particle size) and mixtures of increasing polarity of hexanes:ethyl acetate $(100: 0 \rightarrow 50: 50)$ as the mobile phase, affording compounds 10 (30 mg) and 11 (40 mg). A portion of the $S$. globulifera resin (100 g) was also submitted to the procedures as describe above furnishing the same compounds 8-11.

One-dimensional and 2-D NMR spectra of compounds 8-11 were acquired in a Brucker DRX500 NMR spectrometer (Brucker, Santa Barbara, CA, USA) operating at a frequency of $500 \mathrm{MHz}$ for ${ }^{1} \mathrm{H}$ and $125 \mathrm{MHz}$ for ${ }^{13} \mathrm{C}$ by using $\mathrm{CDCl}_{3}$ and $\mathrm{CD}_{3} \mathrm{OD}+0.1 \%$ TFA as deuterated solvents (Sigma Aldrich, St. Louis, MO, USA). High-resolution mass spectrometry data of compounds 8 and $\mathbf{9}$ were obtained by direct infusion in negative ionization mode on an orbitrap mass spectrometer (Thermo Scientific, San Jose, CA, USA).

Guttiferone E (8): yellow amorphous powder; UV (HPLC-online) $\lambda_{\text {max }}$ : 249.6, $354.4 \mathrm{~nm} ;{ }^{1} \mathrm{H}$ and ${ }^{13} \mathrm{C}$ NMR data as reported by Gustafson et al., 1992 [10]. HRESIMS negative mode $m / z 601.3546$ [M - H] $^{-}$ (calcd. for $\mathrm{C}_{38} \mathrm{H}_{50} \mathrm{O}_{6}, 601.3529$ ), 525.3232, 183.0116, 109.0284 .

Oblongifolin B (9): yellow amorphous powder; UV (HPLC-online) $\lambda_{\text {max }}: 244.9,350.9 \mathrm{~nm} ;{ }^{1} \mathrm{H}$ and ${ }^{13} \mathrm{C}$ NMR data as reported by Hamed et al., 2006 [12]. HRESIMS negative mode $m / z 601.3546$ [M - H] (calcd. for $\mathrm{C}_{38} \mathrm{H}_{50} \mathrm{O}_{6}, 601.3529$ ), 525.3232, 333.1349, 183.0116, 109.0284.

$\beta$-Amyrin (10): white needles; ${ }^{1} \mathrm{H}$ and ${ }^{13} \mathrm{C}$ NMR data as reported by Lima et al., 2004 [13]. 
Glutinol (11): white needles; ${ }^{1} \mathrm{H}$ and ${ }^{13} \mathrm{C}$ NMR data as reported by Mahato et al., 1981 [14]

\subsection{HPLC Analyses of Botanical Sources and BRP}

The chromatographic profiles of BRP samples, and the resins of D. ecastaphyllum and S. globulifera were obtained by using an HPLC-DAD method on a Waters 1500-series setup (Milford, CT, USA) with an Ascentis Express C18 column $(2.7 \mu \mathrm{m}, 150 \times 4.60 \mathrm{~mm})$ as the stationary phase and mixtures of water with $0.1 \%$ formic acid (B) and acetonitrile (B) as the mobile phase. The flow rate was set at $1.0 \mathrm{~mL} / \mathrm{min}$ in a gradient elution mode as follows: $20 \rightarrow 50 \% \mathrm{~B}$ in $40 \mathrm{~min}, 50 \rightarrow 100 \% \mathrm{~B}$ in $90 \mathrm{~min}, 100 \%$ B (isocratic) until $95 \mathrm{~min}, 100 \rightarrow 20 \%$ B until $100 \mathrm{~min}, 20 \% \mathrm{~B}$ (isocratic) up to $105 \mathrm{~min}$. Benzophenone $(20 \mu \mathrm{g} / \mathrm{mL})$ was used as the internal standard (i.s.). One milligram of each resin sample or propolis extract was dissolved in methanol and subjected to chromatographic analysis. Standard compounds liquiritigenin (1), isoliquiritigenin (2), formononetin (3), vestitol (4), neovestitol (5), medicarpin (6), and 7-O-neovestitol (7) were available in the isolated compound library of the laboratory. The standard compounds 1-7 and the isolated compounds guttiferone E (8) and oblongifolin B (9) were dissolved in methanol $(20 \mu \mathrm{g} / \mathrm{mL})$ for HPLC analyses.

Supplementary Materials: The ${ }^{1} \mathrm{H}$ and ${ }^{13} \mathrm{C}$ NMR spectra of isolate compounds 8 and 9 are available online.

Author Contributions: Conceptualization, G.V.C.-C., J.A.A.M., M.G., J.C.A.S.d.C. and J.K.B.; methodology, G.V.C.-C., J.A.A.M. and J.K.B.; isolation procedures, G.V.C.-C., J.A.A.M. and M.H.T.; resources, J.K.B.; plant identification, M.G.; field research, G.V.C.-C., J.C.A.S.d.C. and J.K.B.; manuscript preparation, G.V.C.-C., J.A.A.M. and J.K.B.; funding acquisition, J.K.B. All authors have read and agreed with the published version of the manuscript.

Funding: This research was funded by São Paulo Research Foundation (FAPESP, grants \#2017/04138-8, 2017/26252-7, \#2018/13700-4 and \#2019/01697-1), Coordination for the Improvement of Higher Education Personnel (CAPES) and the National Council for Scientific and Technological Development (CNPq).

Acknowledgments: Jairo Kenupp Bastos would like to register that it was an honor to be a student of James D. McChesney, an outstanding scientist and human being.

Conflicts of Interest: The authors declare no conflict of interest.

\section{References}

1. Salatino, A.; Salatino, M.L.F. Brazilian red propolis: Legitimate name of the plant resin source. MOJ Food Process. Technol. 2018, 6, 21-22. [CrossRef]

2. Daugsch, A.; Moraes, C.S.; Fort, P.; Park, Y.K. Brazilian red propolis-Chemical composition and botanical origin. Evidence-Based Complement. Altern. Med. 2008, 5, 435-441. [CrossRef] [PubMed]

3. Silva, B.B.; Rosalen, P.L.; Cury, J.A.; Ikegaki, M.; Souza, V.C.; Esteves, A.; Alencar, S.M. Chemical composition and botanical origin of red propolis, a new type of brazilian propolis. Evidence-Based Complement. Altern. Med. 2008, 5, 313-316. [CrossRef] [PubMed]

4. Piccinelli, A.L.; Lotti, C.; Campone, L.; Cuesta-Rubio, O.; Campo Fernandez, M.; Rastrelli, L. Cuban and Brazilian red propolis: Botanical origin and comparative analysis by high-performance liquid chromatography-photodiode array detection/electrospray ionization tandem mass spectrometry. J. Agric. Food Chem. 2011, 59, 6484-6491. [CrossRef] [PubMed]

5. do Nascimento, T.G.; dos Santos Arruda, R.E.; da Cruz Almeida, E.T.; dos Santos Oliveira, J.M.; Basílio-Júnior, I.D.; Celerino de Moraes Porto, I.C.; Rodrigues Sabino, A.; Tonholo, J.; Gray, A.; Ebel, R.A.E.; et al. Comprehensive multivariate correlations between climatic effect, metabolite-profile, antioxidant capacity and antibacterial activity of Brazilian red propolis metabolites during seasonal study. Sci. Rep. 2019, 9, 1-16. [CrossRef] [PubMed]

6. Rufatto, L.C.; dos Santos, D.A.; Marinho, F.; Henriques, J.A.P.; Roesch Ely, M.; Moura, S. Red propolis: Chemical composition and pharmacological activity. Asian Pac. J. Trop. Biomed. 2017, 7, 591-598. [CrossRef]

7. Fasolo, D.; Bergold, A.M.; von Poser, G.; Teixeira, H.F. Determination of benzophenones in lipophilic extract of Brazilian red propolis, nanotechnology-based product and porcine skin and mucosa: Analytical and bioanalytical assays. J. Pharm. Biomed. Anal. 2016, 124, 57-66. [CrossRef] [PubMed] 
8. Trusheva, B.; Popova, M.; Bankova, V.; Simova, S.; Marcucci, M.C.; Laguna Miorin, P.; Da, F.; Pasin, R.; Tsvetkova, I. Bioactive constituents of brazilian red propolis. Evidence-Based Complement. Altern. Med. 2006, 3, 249-254. [CrossRef] [PubMed]

9. Dantas Silva, R.P.; Machado, B.A.S.; de Barreto, G.A.; Costa, S.S.; Andrade, L.N.; Amaral, R.G.; Carvalho, A.A.; Padilha, F.F.; Barbosa, J.D.V.; Umsza-Guez, M.A. Antioxidant, antimicrobial, antiparasitic, and cytotoxic properties of various Brazilian propolis extracts. PLoS ONE 2017, 12, e0172585. [CrossRef] [PubMed]

10. Gustafson, K.R.; Blunt, J.W.; Munro, M.H.G.; Fuller, R.W.; McKee, T.C.; Cardellina, J.H.; McMahon, J.B.; Cragg, G.M.; Boyd, M.R. The guttiferones, HIV-inhibitory benzophenones from Symphonia globulifera, Garcinia livingstonei, Garcinia ovalifolia and Clusia rosea. Tetrahedron 1992, 48, 10093-10102. [CrossRef]

11. Li, J.; Gao, R.; Zhao, D.; Huang, X.; Chen, Y.; Gan, F.; Liu, H.; Yang, G. Separation and preparation of xanthochymol and guttiferone $\mathrm{E}$ by high performance liquid chromatography and high speed counter-current chromatography combined with silver nitrate coordination reaction. J. Chromatogr. A 2017, 1511, 143-148. [CrossRef] [PubMed]

12. Hamed, W.; Brajeul, S.; Mahuteau-Betzer, F.; Thoison, O.; Mons, S.; Delpech, B.; Van Hung, N.; Sévenet, T.; Marazano, C.; Oblongifolins, A.-D. Polyprenylated benzoylphloroglucinol derivatives from Garcinia oblongifolia. J. Nat. 2006, 69, 774-777.

13. Da Paz Lima, M.; De Campos Braga, P.A.; Macedo, M.L.; Da Silva, M.F.D.G.F.; Ferreira, A.G.; Fernandes, J.B.; Vieira, P.C. Phytochemistry of Trattinnickia burserifolia, T. rhoifolia, and Dacryodes hopkinsii: Chemosystematic implications. J. Braz. Chem. Soc. 2004, 15, 385-394. [CrossRef]

14. Mahato, S.B.; Das, M.C.; Sahu, N.P. Triterpenoids of Scoparia dulcis. Phytochemistry 1981, 20, $171-173$. [CrossRef]

15. Wink, M. Evolution of secondary metabolites in legumes (Fabaceae). South African J. Bot. 2013, 89, 164-175. [CrossRef]

16. Bankova, V.; Popova, M.; Trusheva, B. The phytochemistry of the honeybee. Phytochemistry 2018, 155, 1-11. [CrossRef] [PubMed]

Sample Availability: Samples of the compounds 1-11 are available from the authors.

(C) 2020 by the authors. Licensee MDPI, Basel, Switzerland. This article is an open access article distributed under the terms and conditions of the Creative Commons Attribution (CC BY) license (http://creativecommons.org/licenses/by/4.0/). 